\title{
O DESEJO HOMOERÓTICO NO CONTO “OBS-CENO”, DE ANTONIO DE PÁDUA
}

\author{
Flávio Pereira Camargo*
}

RESUMO: O objetivo deste artigo é fazer uma análise do conto “Obs-ceno”, de Antonio de Pádua, incluído no livro Abjetos: desejos, publicado em 2010, a partir de uma perspectiva entre literatura e homoerotismo com fundamentação nas discussões teóricas dos estudos de Didier Eribon (2008), Eliane Robert Moraes (2003), Georges Bataille (1987), Julia Kristeva (1982), Octávio Paz (1995, 2014) e Zygmunt Bauman (2004). Na leitura do conto, pretende-se evidenciar como as questões referentes à identidade, à autodescoberta de si e do desejo homoerótico do protagonista Sérgio são representados na tessitura da narrativa. Trata-se de um jovem cujo desejo homoerótico leva-o a ter consciência de sua própria identidade, provocando uma ruptura e uma transgressão com a interdição do erotismo dos corpos e dos desejos por meio de uma linguagem que encena o próprio erotismo dos corpos. Aspectos concernentes à questão do armário e da injúria, compreendidos como elementos constitutivos de uma subjetividade gay, também serão analisados no decorrer do ensaio.

PALAVRAS-CHAVE: Abjeção; Antonio de Pádua; Desejo homoerótico; Obsceno.

Ao contrário das outras palavras, a palavra obscena não só representa mas é a própria coisa.

Lucienne Frappier-Mazur

$\mathrm{O}$ adjetivo obsceno, etimologicamente, vem da palavra latina obscenus, a, um, cujo sentido expressaria uma linguagem augural, de "mau augúrio", que ofende o cerne da moral e dos bons costumes. A obscenidade pode se manifestar em palavras, ações ou imagens,

\footnotetext{
* Professor adjunto de Literatura Brasileira na Faculdade de Letras, da Universidade Federal de Goiás (UFG), com atuação na Graduação e no Programa de Pós-Graduação em Letras e Linguística. E-mail: camargolitera@gmail.com
} 
que, por sua linguagem desprovida de pudor, choca os moralistas pela falta de decoro, pela vulgaridade, pela devassidão.

Eliane Robert Moraes, no artigo “O efeito obsceno”, afirma que a questão da nomeação é um aspecto central para se pensar a concepção moderna de pornografia. Para a autora, "a nomeação das posições sexuais e das partes mais secretas do corpo, valendo-se dessa "língua técnica" cujos termos foram expulsos da decência" (MORAES, 2003, p. 123) contribui para o efeito obsceno que se produz no leitor. É essa linguagem licenciosa que dissemina imagens, gestos, posições e palavras consideradas como obscenas, que ferem o pudor e a moral da sociedade, ao expor uma representação explícita do sexo como pedra de toque.

O cerne da questão diz respeito à nomeação da "coisa em si" por meio de minuciosos detalhes advindos do uso de uma "linguagem técnica" que nomeia e renomeia todas as partes do corpo, com suas designações anatômicas, com os termos mais vulgares que se possa imaginar para detalhar, inclusive, partes anatômicas consideradas como abjetas:

os "nomes técnicos" como excessos de linguagem [...], além de evocarem seus referentes, também atuam como seus substantivos. À medida que a linguagem da transgressão incita no leitor um desejo autêntico, ela ganha autonomia, tornando-se uma "realidade independente" que muitas vezes supera, ou corrige, o desejo provocado pelo objeto real (MORAES, 2003, p. 130).

Pode-se dizer que há uma transgressão por meio da linguagem e uma linguagem da transgressão, cujos “excessos de linguagem” produzem efeitos obscenos no leitor, ao despertar nele um desejo latente, um desejo que pulsa na carne. Não se trata apenas de uma temática erótica ou homoerótica como elemento central de uma narrativa, mas de uma linguagem que é em si mesma impregnada de erotismo. Uma linguagem é considerada obscena quando há a presença de um vocabulário técnico utilizado para nomear aquilo que o pudor, a moral e os bons costumes excluíram do cotidiano.

Nesse sentido, o título do conto de Pádua, "Obs-ceno", revela ao leitor duas vertentes. Inicialmente, remete àquilo que é considerado como imoral, como obsceno, justa- 
mente porque se trata de algo que fere o pudor e, portanto, é silenciado pelos valores morais e sociais de uma sociedade. Além disso, o vocábulo "obs-ceno" remete a algo que está fora de cena, portanto, excluído na e pela sociedade justamente por ser considerado como abjeto, como imoral. A partir desta compreensão é possível depreender uma conexão entre o título do conto e o seu enredo, tendo em vista que o desejo homoerótico masculino que perpassa a trama da narrativa é considerado como abjeção, como obscenidade, passível, portanto, de ser expurgado da vida social, de ser colocado fora de cena.

O conto em tela é narrado em primeira pessoa pelo protagonista Sérgio. Uma narrativa de si, do eu, por meio da qual ele resgata elementos constitutivos de sua identidade e de seu desejo.

O que eu sentia era uma realidade estranha ao meu dia a dia. Nada ali parecia meu ou eu de verdade. Sentia ser um outro que me invadia e vivia por mim. Quando - pensava calado - até então havia tido consciência das coisas estranhas que sentia? Nunca soube. Jamais iria saber (SILVA, 2010, p. 63).

O excerto inicial do conto é emblemático no que diz respeito ao processo de autodescoberta da própria identidade, que provoca no protagonista certo estranhamento em relação a si mesmo e à sua identidade. Uma identidade que lhe é revelada pelo olhar do outro, pelo olhar do pai que condena o filho por ser diferente. Trata-se de uma busca por si e de uma tentativa de compreensão da própria identidade. O estranhamento que Sérgio sente advém do fato de ele se sentir estranho e de se ver como um estranho em decorrência do fato de ele ser visto como um ser abjeto, estranho, como uma "marmota": "Naqueles dias minha alma ficava prenhe. De vontade, de desejo, de coisas quentes. Um dia meu pai falou que tudo o que eu inventava não passava de marmota. Até hoje não consigo decifrar o significado do termo” (SILVA, 2010, p. 63, grifo do autor).

Didier Eribon é categórico ao se referir à interpelação heterossexual à qual os gays são submetidos cotidianamente ao afirmar que

o gay que decide se dizer, expõe-se ao comentário irônico ou condescendente, e, às vezes, à má acolhida, e aquele que prefere calar-se 
coloca-se numa situação falsa e, ao menos, dependente. Ao primeiro, passamos a lição. Do segundo, zombamos. Sempre é a dissimetria que está em ação: o heterossexual sempre tem um privilégio sobre o homossexual. É ele quem decide a atitude a ser adotada e o sentido que vai dar aos gestos e às falas do homossexual (2008, p. 74 , grifo do autor).

O julgamento do pai é impiedoso e deixa marcas profundas na memória do protagonista. O substantivo "marmota" denota algo que pode ser compreendido ao mesmo tempo como brincadeira, comportamento burlesco, momice ou pessoa desengonçada, deselegante, mal-ajambrada. Neste sentido, o comportamento de Sérgio é considerado pelo pai, ainda na infância, como algo obsceno, uma espécie de aleijão, uma vez que o ato de nomear o filho como "marmota" pode e deve ser compreendido como um ato de injúria que expõe uma vulnerabilidade social e psicológica daquele que sofre a injúria.

"Viado nojento" ("sapata nojenta") não são simples palavras lançadas en passant. São agressões verbais que marcam a consciência. São traumatismos sentidos de modo mais ou menos violento no instante, mas que se inscrevem na memória e no corpo (pois a timidez, o constrangimento, a vergonha são atitudes corporais produzidas pela hostilidade do mundo exterior). E uma das consequências da injúria é moldar a relação com os outros e com o mundo. E, por conseguinte, moldar a personalidade, a subjetividade, o próprio ser de um indivíduo (ERIBON, 2008, p. 27).

São várias as formas da violência. Ela pode ser social, psicológica, física e simbólica. Em ambos os casos, a violência deixa marcas, abre sulcos profundos na memória, no corpo e na alma daquele que a sofre. $\mathrm{O}$ ato da injúria expõe a consciência ferida como elemento constitutivo de uma identidade gay, pois em relações marcadas por micro e macrorrelações de poder, o ato de nomear o outro e de se distinguir dele através de um traço distintivo que estigmatiza a identidade de outrem provoca no outro uma conscientização de si, de sua própria identidade: “o homossexual só pode ser o objeto do discurso e torna-se insuportável tão logo pretende ser o sujeito" (ERIBON, 2008, p. 73).

Aquele que nomeia o outro o toma como "objeto" passível de perquirição, de desapossamento de sua própria identidade, fazendo com que o outro tome consciência da 
exclusão e da abjeção a que está sujeito: “A injúria me faz saber que sou alguém que não é como os outros, que não está na norma. Alguém que é viado [queer]: estranho, bizarro, doente. Anormal” (ERIBON, 2008, p. 28, grifo do autor).

O segredo de Sérgio como “os segredos das flores não são revelados nem ao mais puro mortal" (SILVA, 2010, p. 63). A metáfora revela ao leitor que a identidade gay do protagonista, os seus desejos, os seus sentimentos e as suas emoções são segredos ainda em processo de descobrimento, que fazem parte de um processo de autodescoberta de si. Segredos que ainda se encontram no armário, mas que estão à flor da pele, dando sinais de sua força vital e atávica.

São estas sensações, estes sentimentos e desejos que provocam uma inquietação no protagonista, porque o desejo desperta em Sérgio uma potencialidade erótica, uma necessidade vital em possuir o outro que desperta nele o desejo contido.

\begin{abstract}
Bastava ver o homem que ficava todo pegajoso. Era algo meio nojento, porque as partes de baixo ficavam intumescidas, lubrificadas. A garganta ficava seca, boca molhada. Os olhos ficavam atentos, o cérebro sonhando. A bunda relaxava, o pênis solto na cueca se exibia todo seguro de si. [...]. Aquela sensação de bem-estar molestava minha vida, pois concomitante a essa sensação, o mal-estar sentido aparecia como vazio interno, de forma que nunca me compreendia e sempre estava à procura de (SILVA, 2010, p. 63-64).
\end{abstract}

Para Georges Bataille (1987, p. 20), “o erotismo é na consciência do homem aquilo que põe nele o ser em questão" e é, ainda, o responsável por levar o homem a buscar constantemente por um objeto de desejo que corresponda à interioridade do seu desejo. Sérgio busca fora de si, naquele que é objeto de investimento afetivo e sexual, a sua completude. Seres incompletos que somos, buscamos no outro a nossa completude, a nossa continuidade e a possibilidade de satisfação de um desejo interior: "só os homens fizeram de sua atividade sexual uma atividade erótica, e o que diferencia o erotismo da atividade sexual simples é uma procura psicológica independente do fim natural encontrado na reprodução e na preocupação das crianças” (BATAILLE, 1987, p. 10). 
Sérgio está “à procura de” um objeto que satisfaça seu desejo erótico. Fato que revela essa busca incessante pelo outro do seu desejo, que desperta nele sentimentos, emoções e desejos latentes, interditados pelas normas morais e sociais. O sujeito responsável por despertar em Sérgio a latência do seu desejo é outro homem, o que contribui para colocar o seu ser em questão. A expressão “à procura de”, nesse sentido, também pode ser compreendida como a tentativa de o protagonista compreender a sua identidade, a sua existência, marcada por sentimentos de angústias mudas em relação à própria identidade que é estigmatizada pelo pai.

No conto em tela, esse desejo de Sérgio e, consequentemente, o seu comportamento no meio social e a sua prática sexual, que são considerados como obscenos e abjetos por seus familiares, faz com que ele sofra atos de injúria resultantes de injunções morais e sociais, que marcam a sua subjetividade, o que remete à questão do armário e da injúria como elementos constitutivos de uma subjetividade gay.

É esse desejo latente que propicia a Sérgio um processo de autodescoberta de si, dos seus desejos, do próprio corpo e de sua identidade:

Diante do espelho, deitado na larga cama do quarto fechado: olhome. Lanço-me como estranho ao outro do espelho que se espelha em mim. [...]. Abria as pernas frente ao clarão especular: um belo par de pernas peludas. Coxas proporcionalmente grossas. No meio das pernas, a marca. Não estava ferrado. Queria ser ou estar sendo. Mas havia a marca: visível, irreversível. O falo era a inscrição material do meu ser no universo simbólico. Ali eu via, naquele instante, apenas o pênis. Peludo. O saco endurecido, ora amortecido, mas firme e resistente: esperando o momento final. Tocava com calma os pelos. Acariciava o pau. [...]. Quando tomava nas mãos: pelos, pica e saco - sobravam-me as virilhas e todo o meu corpo na posição xeque-mate. [...]. Abria a bunda e via no meio das nádegas o furo molhado, o furo lubrificado, o furo pedinte. Era também aquilo que não entendia. Prostrava-me passivo naquela cama esperando uma alma que pudesse violar meu corpo, que consentisse na pederastia (SILVA, 2010, p. 64-65).

O excerto acima é exemplar para a discussão proposta neste ensaio sobre os obscenos desejos ou sobre os desejos obscenos. O leitor percebe, inicialmente, que a linguagem 
utilizada pelo protagonista para narrar os fatos referentes aos prazeres solitários, em um momento de autodescoberta do próprio corpo, é construída a partir de uma nomeação técnica das partes do corpo. Sérgio se vale de uma linguagem licenciosa, obscena, para resgatar, nomear e descrever os detalhes de seu corpo e dos desejos que a autodescoberta lhe proporciona. As imagens recuperadas pela memória de Sérgio provocam no leitor um efeito obsceno em decorrência da nomeação da "coisa em si", do ato em si e das imagens que este ato evoca.

Em um segundo momento, o leitor percebe a inscrição material e simbólica de Sérgio no universo masculino em decorrência da imagem bélica do falo, farto, firme, resistente, com pelos e saco. Estes elementos simbólicos podem ser considerados como marcas distintivas que materializam um corpo masculino, que se difere de um corpo feminino. A inscrição corporal, material e simbólica no universo masculino não impede que Sérgio tenha desejo por outro corpo masculino.

Há, portanto, uma transgressão no conto. Uma transgressão que ocorre, em um primeiro plano, no nível da linguagem licenciosa que é utilizada para nomear o ato em si, o ato da masturbação que provoca no protagonista o desejo e o autoconhecimento do próprio corpo. Em um segundo plano há uma transgressão que diz respeito às zonas interditadas como objeto de prazer, como, por exemplo, a bunda, que se abre, revelando "o furo molhado, o furo lubrificado, o furo pedinte", pronto para ser possuído, violado pelo outro, objeto de desejo de Sérgio.

Para Georges Bataille,

a nudez se opõe ao estado fechado, isto é, ao estado de existência descontínua. É um estado de comunicação que revela a busca de uma continuidade possível do ser para além do voltar-se sobre si mesmo. Os corpos se abrem para a continuidade através desses canais secretos que nos dão o sentimento da obscenidade (1987, p. 14). 
É justamente o que ocorre no conto em tela. Sérgio, desnudo, com o corpo exalando desejos, tesão e carência pelo objeto de seu desejo se abre para estabelecer uma relação de continuidade com o outro. Seres descontínuos que somos, buscamos a completude no outro. Essa necessidade do outro revela um sentimento de solidão latente do protagonista.

Ali, o ânus só pedia. Não: implorava. Desejava carne: apenas dura. Tinha que fazer alguma coisa. Sozinho naquele estado ia cometer algumas loucuras (de outras vezes já tinha tomado veneno de rato, uísque em demasia, mais de vinte cápsulas de diazepan, cinco pacotinhos de maconha e duas pedras de craque) (SILVA, 2010, p. 66).

O sentimento de solidão de Sérgio se acentua principalmente pelo fato de ele ter consciência da própria solidão, do estar só, em decorrência da ausência de vínculos afetivos e familiares que possam usurpá-lo da condição de errante. O sentimento de solidão diz respeito ao fato de o homem sentir-se sozinho, e o "saber-sozinho, isolado do mundo e alheio a si mesmo" (PAZ, 2014, p. 189) vincula-se à consciência da própria solidão.

É em decorrência desse sentimento de solidão e da consciência da própria solidão que Sérgio buscará no ex-namorado Alan uma espécie de comunhão, uma vez que "as dores de amor são dores de solidão. Comunhão e solidão, desejo de amor, se opõem e se complementam" (PAZ, 2014, p. 189).

[...] depois de muito me preparar para a humilhação, liguei para Alan. Tínhamos namorado por mais de oito meses, até que ele encontrou um professor de biologia e com ele foi embora, recebendo na mesma moeda a paga pelo meu abandono. [...]. Alô! Digo. Oi! Sérgio, manda lá! Ele sempre dizia isso. Alan, você está muito ocupado agora? Triste cantada de quem está desesperado por uma trepada. Qualquer um entende. Quando todos os laços entre pessoas são desatados e num telefonema atendido procuram-se saber do tempo disponível do chamado, tá na cara: é uma cantada na certa. Melhor: é um aviso: socorro, me olhem, estou a ponto de explodir! Socorro, gostem de mim porque eu não me gosto mais! Tá querendo que eu vá aí ou tu vem aqui? Perguntou certeiro, na mosca. Vem! (SILVA, 2010, p. 67). 
Para Zygmunt Bauman (2004, p. 12), no "líquido cenário da vida moderna" as relações afetivas tornam-se mais rarefeitas, o que remete à fragilidade dos vínculos humanos, dos laços afetivos e ao sentimento de insegurança diante do abandono. São relações descartáveis que fazem com que os sujeitos se tornem mais solitários, "desesperados por 'relacionar-se" (BAUMAN, 2004, p. 8) em momentos de aflição, nos quais o sentimento de solidão e a consciência da própria solidão se tornam mais verticalizados.

No caso de Sérgio, o ato de se masturbar e o prazer solitário que sente ao tocar o próprio corpo não abrandam o seu sentimento agudo de carência, a falta de outro corpo que possa saciar os seus desejos, a sua fome por sexo e a sua solidão crônica. A humilhação a que se refere Sérgio diz respeito ao fato de Alan, após terminar com ele, rejeitá-lo, não atender suas ligações e negar ao ex-namorado a possibilidade de um recomeço ou de um momento efêmero que fosse para suavizar as suas dores de alma.

Para Octávio Paz,

a solidão é o substrato último da condição humana. O homem é o único ser que se sente sozinho, o único que é busca de outro. Sua natureza $[. .$.$] consiste em aspirar a realizar-se em outro. O homem é$ nostalgia e busca de comunhão. Por isso, toda vez que sente a si mesmo, sente-se como carência de outro, como solidão (2014, p. 189).

Para aplacar esse sentimento de solidão, Alan resolve se encontrar com Sérgio, tendo com ele uma relação sexual que faz com que o protagonista se sinta desejado novamente. Embora seja uma relação que tenha como objetivo único abrandar o desejo latente dos dois personagens, ambos, seres descontínuos, solitários e errantes, buscam a sua completude um no outro.

Entrou, esperou que eu fechasse a porta, tocou minha nuca, virou meu rosto e furtou-me uns dois quilos de beijos num único trago. Despiu meu ser cansado de esperar. Tocou tudo em mim. Sentiu minha bunda: molhada. O ânus: convidativo. Cheirou. Disse-lhe que não havia tido tempo de me banhar para ele, uma vez que veio rápido. Não importa, respondeu. Encostou-me na parede como só ele sabe fazer. Pediu para que eu empinasse a bunda. [...]. De baixo ele tinha uma visão. Do alto, só sentia: a boca morder minhas pernas, 
lamber minha bunda, penetrar meu ânus com a ponta afiada da língua que tinha. Cheirava o meio, abria o lugar central, atirava rajadas de saliva (SILVA, 2010, p. 67-68).

Entre Sérgio e Alan não há pudor em relação ao corpo um do outro. Não há interdição de zonas erógenas. O que há, de fato, é uma entrega incondicional ao outro, uma exploração do corpo do outro através de todos os sentidos, seja do olfato, do tato, da visão, do paladar ou da audição. Uma relação que tem como base o erotismo dos corpos e o desejo que esses corpos despertam no objeto de desejo a partir das sensações, dos sentidos e da imaginação.

Para Octavio Paz, “os sentidos, sem perder os seus poderes, convertem-se em servidores da imaginação e fazem-nos ouvir o inaudito e ver o que é imperceptível” (1995, p. 9). O erotismo, para Paz, é cerimônia e representação: “O erotismo é sexualidade transfigurada: metáfora. O agente que move tanto o acto erótico como o poético é a imaginação. É a potência que transfigura o sexo em cerimónia e rito, a linguagem em ritmo e metáfora" (PAZ, 1995, p. 9-10). Neste sentido, há o estabelecimento de um jogo erótico por meio da linguagem que encena o próprio erotismo dos corpos, que aguça o efeito obsceno provocado no leitor a partir da nomeação explícita das posições, dos atos em si e da conjunção carnal do ato sexual entre os dois corpos sem os filtros da moralidade e da higienização da linguagem.

Não havia machucão, aranhão, rasgão ou sangramento. Só havia pau e couro fodendo num ritmo que me fazia grunhir de gozo. Depositava em mim uma porção suficiente de esperma que daria para providenciar vários embriões. Mas o meu útero é seco. Minhas entranhas são macho. Não há mandrágora que tenha poder sobre esse destino. O leite: coalha. Terra: infecunda, embora destemida para o prazer. E basta (SILVA, 2010, p. 68).

A linguagem licenciosa nomeia, descreve e encena minuciosamente o ato erótico entre Sérgio e Alan, revelando ao leitor uma relação sexual que não tem como finalidade última a reprodução. Pelo contrário, ela tem como objetivo saciar o desejo e o prazer dos 
corpos envolvidos, sobretudo porque "o erotismo defende a sociedade dos assaltos da sexualidade, mas, também nega a função reprodutiva" (PAZ, 1995, p. 14).

Esta negação da função reprodutiva em detrimento do prazer é depreendida das metáforas presentes ao final do conto: "O leite: coalha. Terra: infecunda, embora destemida para o prazer. E basta". O útero é infértil e seco. A terra é infecunda. O leite, metáfora do esperma abundante que jorra do corpo de Alan, coalha, não tendo como finalidade última o desenvolvimento de embriões que possam garantir a procriação e a reprodução, mas apenas propiciar prazer a ambos. Além disso, as metáforas supracitadas remetem àquela impossibilidade de se manter os laços afetivos no contexto da modernidade líquida.

Pode-se concluir, ao final deste ensaio, que a linguagem licenciosa utilizada por Pádua na construção do conto "Obs-ceno" desnuda os obscenos desejos interditados pela moralidade e pelos "bons costumes", além de trazer à tona sentimentos, emoções e desejos que são inerentes à condição humana.

Amar e desejar o outro, sentir a carência do objeto de desejo, sentir-se solitário e ter consciência da própria solidão são questões que assolam a subjetividade de qualquer ser humano, mas em se tratando de uma subjetividade gay esses sentimentos se tornam mais agudos, revelando ao leitor a latência de um desejo que é interditado e considerado como abjeto. Para Julia Kristeva, “a abjeção, em si, é imoral, tenebrosa, oscilante, suspeita” (1982, p. 4). Neste sentido, a abjeção do corpo gay, do desejo gay e de suas práticas sexuais se dá justamente pelo fato de transgredir as normas morais e sociais, precisamente porque é "aquilo que perturba uma identidade, um sistema, uma ordem. Aquilo que não respeita os limites, os lugares, [e] as regras" (KRISTEVA, 1982, p. 4) que é considerado como abjeto.

\section{THE HOMOEROTIC DESIRE IN THE TALE “OBS-CENO” BY ANTONIO DE PÁDUA}

ABSTRACT: This paper aims to analyze the tale "Obs-ceno", by Antonio de Pádua, included in the book Abjetos: desejos, published in 2010, from a perspective between literature and homoeroticism, based on the theoretical discussions of Eribon Didier's studies (2008), Eliane Robert Moraes (2003), Georges Bataille (1987), Julia Kristeva (1982), Octávio Paz (1995, 2014), and Zygmunt Bauman (2004). When reading the tale, we try to show how questions referring to the identity, to the self- 
discovery of the self and the homoerotic desire of the protagonist Sérgio are represented in the texture of the narrative. Sérgio is a young man whose homoerotic desire leads him to be aware of his own identity, provoking a rupture and a transgression with the interdiction of the eroticism of bodies and desires through a language that stages the very eroticism of bodies. Aspects concerning the issue of closet and slander, understood as constitutive elements of a gay subjectivity, will also be analyzed in the course of the essay.

KEYWORDS: Abjection; Antonio de Pádua; Homoerotic desire; Obscene.

\section{REFERÊNCIAS}

BAUMAN, Zygmunt. Amor líquido: sobre a fragilidade das relações humanas. Rio de Janeiro: Jorge Zahar Ed., 2004.

BATAILLE, Georges. O erotismo. Porto Alegre: L\&PM, 1987.

ERIBON, Didier. Reflexões sobre a questão gay. Rio de Janeiro: Companhia de Freud, 2008.

HOUAISS, Antonio. Dicionário eletrônico Houaiss da língua portuguesa 3.0. Rio de Janeiro: Objetiva, 2009.

KRISTEVA, Julia. Aproximação da abjeção. In: - Poderes do horror: ensaio sobre a abjeção (1982). Trad. Allan Sena. Disponível em: <http://www.academia.edu/18298036/Poderes_do_Horror_de_Julia_Kristeva_Cap\%C3\%ADtulo_1>. Acesso em 10 de maio de 2016.

MORAES, Eliane Robert. O efeito obsceno. Cad. Pagu [on line], n. 20, p.121-130, 2003.

SILVA, Antonio de Pádua Dias da. Obs-ceno. In: . Abjetos: desejos. Olinda: Livro Rápido, 2010. p. 63-68.

PAZ, Octavio. Os reinos de Pã. In: . A chama dupla. Amor e erotismo. Trad. José Bento. Lisboa: Assírio \& Alvim, 1995. p. 9-22.

. A dialética da solidão. In:

O labirinto da solidão. Trad. Ari Roitman e Paulina

Wacht. São Paulo: Cosac Naify, 2014. p. 189-204.

Recebido em: 10/08/2017.

Aprovado em: 20/12/2017. 